\title{
Composition analysis of liquid particles in the Arctic stratosphere under synoptic conditions
}

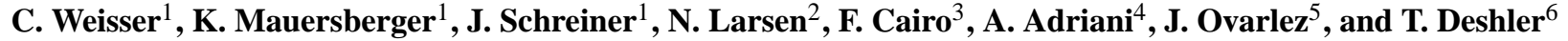 \\ ${ }^{1}$ Max-Planck-Institute for Nuclear Physics, Heidelberg, Germany \\ ${ }^{2}$ Danish Meteorological Institute, Copenhagen, Denmark \\ ${ }^{3}$ Institute for Atmospheric Science and Climate, Consiglio Nazionale delle Ricerche, Rome, Italy \\ ${ }^{4}$ Institute for Interplanetary Space Physics, Consiglio Nazionale delle Ricerche, Rome, Italy \\ ${ }^{5}$ Laboratoire de Meteorologie Dynamique, Ecole Polytechnique, Palaiseau, France \\ ${ }^{6}$ University of Wyoming, Laramie, Wyoming, USA
}

Received: 8 April 2004 - Published in Atmos. Chem. Phys. Discuss.: 12 May 2004

Revised: 7 July 2005 - Accepted: 21 August 2005 - Published: 1 March 2006

\begin{abstract}
Synoptic scale polar stratospheric clouds (PSCs) that formed without the presence of mountain lee waves were observed in early December 2002 from Kiruna/Sweden using balloon-borne instruments. The physical, chemical, and optical properties of the particles were measured. Within the PSC solid particles existed whenever the temperature was below the equilibrium temperature for nitric acid trihydrate and liquid particles appeared when the temperature fell below an even lower threshold about $3 \mathrm{~K}$ above the frost point with solid particles still present. The correlation of liquid supercooled ternary solution aerosols with local temperatures is a pronounced feature observed during this flight; average molar ratios $\mathrm{H}_{2} \mathrm{O} / \mathrm{HNO}_{3}$ were somewhat higher than predicted by models. In addition $\mathrm{HCl}$ has been measured for the first time in liquid aerosols. The chlorine isotope signature served as a unique tool to identify unambiguously $\mathrm{HCl}$ dissolved in STS particles. Within a narrow temperature range of about three degrees above the frost point, the measured average amount of $\mathrm{HCl}$ in liquid particles is below 1 weight\%.
\end{abstract}

\section{Introduction}

Substantial progress has been made during the last few years to understand the formation and distribution of polar stratospheric cloud (PSC) particles, especially over Northern Europe. New instruments and well-organized combinations of experiments on balloon payloads or research aircrafts have advanced our understanding on formation processes, composition, size, phase, and temperature dependence of PSCs. A European-American campaign in 1999/2000 (SOLVE/THESEO 2000) was particularly suc-

Correspondence to: $\mathrm{K}$. Mauersberger

(k.mauersberger@mpi-hd.mpg.de) cessful, producing highlights such as the first stratospheric measurement of solid nitric acid trihydrate (NAT) particles (Voigt et al., 2000) and of unusually large PSC particles within the polar vortex (Fahey et al., 2001). A comprehensive description of many parameters that characterize stratospheric clouds and their environment is now available (Newman et al., 2002).

Today we know that polar stratospheric clouds (PSCs) can consist of solid and liquid particles and their existence is controlled by atmospheric temperatures and relevant gas phase mixing ratios. Apart from sulfuric acid tetrahydrate aerosol, nitric acid trihydrate (NAT) particles have the highest equilibrium temperature $T_{\mathrm{NAT}}$. The critical temperature $T_{\mathrm{STS}}$ below which supercooled ternary solution (STS) droplets exist is well below $T_{\mathrm{NAT}}$, around $3 \mathrm{~K}$ above the frost point $T_{\text {ice }}$. The formation of solid particles requires overcoming a nucleation barrier. Ice freezes out of STS only 3-4 K below the frost point (Koop et al., 2000). Ice particles can serve as a site for the heterogeneous nucleation of NAT particles (Koop et al., 1997). It has become clear that an additional formation process of NAT above $T_{\text {ice }}$ is required to explain many PSC observations (Larsen et al., 2002; Drdla et al., 2003). In contrast to the formation of solid ice or NAT particles there is no nucleation barrier for the growth of liquid STS. Below a certain threshold they begin to swell due to the combined uptake of mainly water and nitric acid (Carslaw et al., 1994). It should also be noted that measurements of liquid and solid particles coexisting in the Arctic stratosphere under lee wave conditions were shown in a recent paper by Deshler et al. (2003b).

Reported in this paper are results from a balloon flight performed from Kiruna, Sweden, in early December 2002. The flight was part of the joint US and European SOLVE2/VINTERSOL project. The measurements captured a very

Published by Copernicus GmbH on behalf of the European Geosciences Union. 
early period of PSC formation in the 2002/2003 arctic winter. On 4 December 2002 between 20 and $27 \mathrm{~km}$ several passes through a PSC were accomplished using controlled up-down motions of the balloon. The flight was carried out exclusively in the cold polar vortex without mountain lee wave activity. The coldest temperatures encountered during the flight were close to but always above $T_{\text {ice. }}$ During the flight the majority of particles were liquid STS droplets, but solid particles were also present. In a separate paper Larsen et al. (2004) shed light on the formation process of the various particles encountered. In the following we address the close correlation of the observed liquid stratospheric particles with the ambient atmospheric temperature. We also derived average $\mathrm{H}_{2} \mathrm{O} / \mathrm{HNO}_{3}$ molar ratios when traveling through cloud formations.

Despite the progress in PSC research, one important minor constituent expected to be present in PSC particles - hydrochloric acid, $\mathrm{HCl}$ - has never been measured in liquid or solid particles in the polar stratosphere, although early attempts were made to estimate the presence of chloride in solid PSC particles (Pueschel et al., 1989; Gandrud et al., 1989). $\mathrm{HCl}$ is a relatively inert reservoir molecule, which can be chemically changed (activated) through heterogeneous reactions in or on PSC particles when the temperature drops well below $200 \mathrm{~K}$. Although the $\mathrm{HCl}$ content of PSCs is of substantial importance, it has only been estimated in atmospheric chemical or microphysical models. Here, we report first measurements of $\mathrm{HCl}$ in STS droplets.

The solubility of $\mathrm{HCl}$ in liquid aerosols has been treated in some detail in a review paper by Carslaw et al. (1997), which describes the fundamental principles of gas-liquid solution interactions and presents some experimental results besides model calculations. The authors derive a number of relationships between gas and liquid phases of participating species, based on Henry's law, to permit calculations of the amount of gases dissolved in liquid aerosols. It is important to recognize in experimental research that just a few degree change in temperature can alter considerably the $\mathrm{H}_{2} \mathrm{SO}_{4}$ concentration in liquid particles and as a consequence the solubility of species that include $\mathrm{HCl}$ and $\mathrm{HBr}$ by orders of magnitude (Luo et al., 1994). Thus, it is difficult to simulate stratospheric conditions in laboratory experiments because of the high sensitivity of trace gas solubility to temperature (Hanson and Ravishankara, 1993; Zhang et al., 1993). As explained in some details later, we can only derive for certain time intervals average values of dissolved $\mathrm{HCl}$ in liquid particles when clouds are encountered. This will limit the accuracy of the measured $\mathrm{HCl}$ abundance since small changes in local temperature will change $\mathrm{HCl}$ in particles considerably.

\section{Meteorological conditions}

In contrast to observations with the same set of instruments during previous winters in mountain induced lee wave con- ditions over northern Scandinavia (Deshler et al., 2003b; Schreiner et al., 2003; Voigt et al., 2000), the observations in early December 2002 were characterized by the presence of a large synoptic-scale region with low temperatures over the North Atlantic. The cooling started around mid November when small regions with temperatures below $T_{\mathrm{NAT}}$ grew to large areas by the end of November and persisted throughout December within the stable arctic vortex. On 4 December, when the measurements took place, the northern part of Scandinavia was clearly inside the cold pool on the $550 \mathrm{~K}$ potential temperature level. Due to low surface winds no orographic induced lee wave activity occurred. The observed PSC particles most probably formed in air parcels that spent several days at temperatures between $T_{\text {ice }}$ and $T_{\mathrm{NAT}}$. Temperature histories (Larsen et al., 2004) show that the air did neither experience temperatures below $T_{\text {ice }}$ nor strong cooling or heating rates, in contrast to the situation one year before in December 2001 (Deshler et al., 2003b). For the first time this kind of comprehensive in situ investigations of polar stratospheric clouds were performed exclusively inside the cold polar vortex without any lee wave activity.

\section{Observations}

Over the last few years, an aerosol composition mass spectrometer (ACMS) has been developed that provided the first chemical analysis of polar stratospheric clouds (Schreiner et al., 1999b). More recent flights, with additional instruments on the gondola, extended the characterization of PSCs and resulted in the first identification of NAT particles (Voigt et al., 2000). Within the ACMS stratospheric particles are concentrated by an aerodynamic focussing lens into a narrow beam, which is directed through a differentially pumped vacuum system. The particle beam finally is stopped and evaporated within a small gold sphere. The evolved gases are analyzed by a mass spectrometer with the ion source directly located at the exit of the small evaporation sphere. Surrounding the beam and the mass spectrometer are liquid helium pumps that provide a sufficiently high pumping speed to perform an analysis of the major content of PSC particles such as $\mathrm{H}_{2} \mathrm{O}$ and $\mathrm{HNO}_{3}$. Atmospheric gases, which enter the analysis system with the particle beam, are present in considerably reduced form due to the high-speed pumping. They are occasionally measured to monitor the performance and stability of the experiment. Since the ACMS has a very high sensitivity for condensed-phase material, the detection of $\mathrm{HCl}$ became possible when, during the last two years, improvements were made in the reduction of background gases and in higher ion beam intensities. Comprehensive descriptions of the focussing lens and the analysis system are provided by Schreiner et al. (1999a, 2002). The complete instrumentation of the gondola has been previously described by Deshler et al. (2003b). 


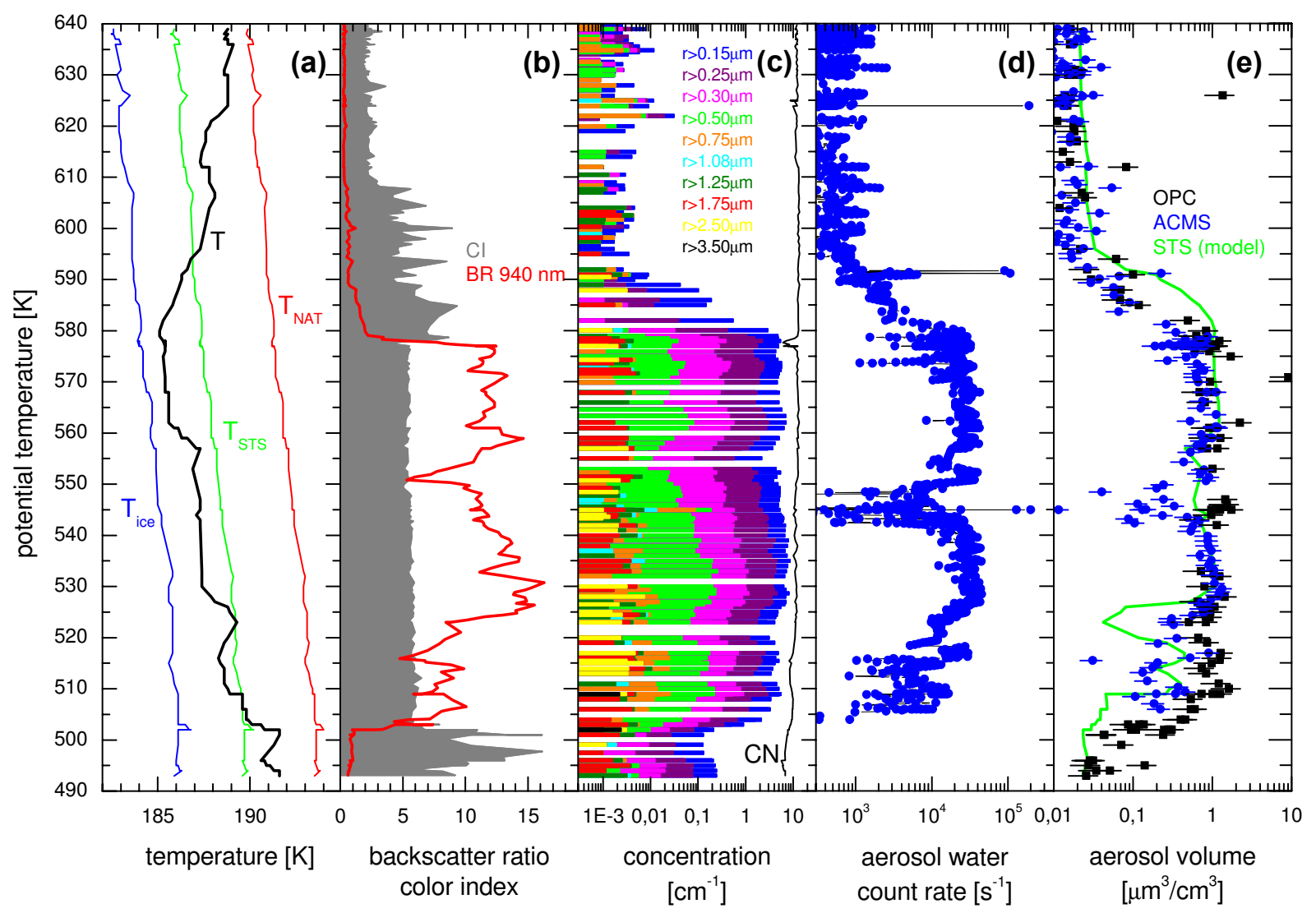

Fig. 1. In-situ measurements during the first ascent through a PSC on 4 December 2002. (a) Measured air temperature, accuracy $\pm 0.5 \mathrm{~K}$, compared to measured $T_{\text {ice }}$ and estimates of $T_{\mathrm{NAT}}$ and $T_{\mathrm{STS}}$. $T_{\mathrm{ice}}$ is measured with a frost point hygrometer (Ovarlez and Ovarlez, 1994). $T_{\mathrm{NAT}}$ is calculated from (Hanson and Mauersberger, 1988) assuming $11 \mathrm{ppbv}$ nitric acid and using the measured water vapor concentrations. $T_{\mathrm{STS}}$ is defined as the temperature at which the liquid particle volume changes by $30 \%$ for a temperature step of $0.1 \mathrm{~K}$ due to the condensation of nitric acid and water, calculated form Carslaw et al. (1995). (b) Backscatter ratio at $940 \mathrm{~nm}$ and color index. (c) Aerosol size and number concentration measured with optical particle counters. (d) Aerosol water (mass 18) measured by the aerosol composition mass spectrometer. (e) Aerosol volume derived from ACMS and OPC measurements in comparison with model predictions for STS using the measured water vapor and the sulfuric acid mixing ratio derived form the background sulfate aerosol measurement, and assuming $11 \mathrm{ppbv}$ nitric acid.

During the flight on 4 December 2002 from Kiruna, Sweden, clouds were present in a temperature range from as low as $184.5 \mathrm{~K}$ to about $187.5 \mathrm{~K}$ within the polar vortex. While the balloon moved up and down in a pressure range of 35 mbar to about $14 \mathrm{mbar}$, three layers of clouds were traversed. Figure 1 presents the measurements for the first ascent of the balloon through the cloud. Within the cloud, temperatures stayed below $T_{\mathrm{NAT}}$, but remained above the frost point (panel a). If temperature had gone well below $T_{\text {ice }}$ and ice particles had formed, large peaks would have appeared in the ACMS water signal. Backscatter ratios at 940 and $480 \mathrm{~nm}$ (Rosen and Kjome, 1991) are shown in panel (b). The color index which is defined as the ratio between the backscatter ratio at 940 and $480 \mathrm{~nm}$ serves as a clear indicator of the particle size. Because of its high values below $500 \mathrm{~K}$ and above $580 \mathrm{~K}$ potential temperature solid particles may be inferred. The phase can also be inferred from depolarization measurements at $532 \mathrm{~nm}$ using a laser backscattersonde (Adriani et al., 1999); however, these measurements are not shown. Particle size and number concentration were measured with four optical particle counters (OPCs) (Deshler and Oltmans, 1998; Deshler et al., 2003a). One OPC measured condensation nuclei $(\mathrm{CN}), \mathrm{r}>0.01 \mu \mathrm{m}$. Three measured particles with $\mathrm{r}>0.15-10.0 \mu \mathrm{m}$, whereas one had a heated inlet to evaporate PSC particles and thus measured the background stratospheric aerosol upon which PSCs condense (Eidhammer and Deshler, 2005). The cumulative size distribution from one OPC with unheated inlet is shown in panel (c). Finally, the particle composition, primarily water and nitric acid, was measured with the ACMS (Schreiner et al., 2002, 2003). In Fig. 1 only water signals are shown (panel d). The time constant of the system for detecting particle water is short and thus water measured on mass 18 is a very good indicator for the onset of particle detection as well as when leaving a cloud. The few spikes in the water signal show the evaporation of single, most probably solid particles in the sphere 


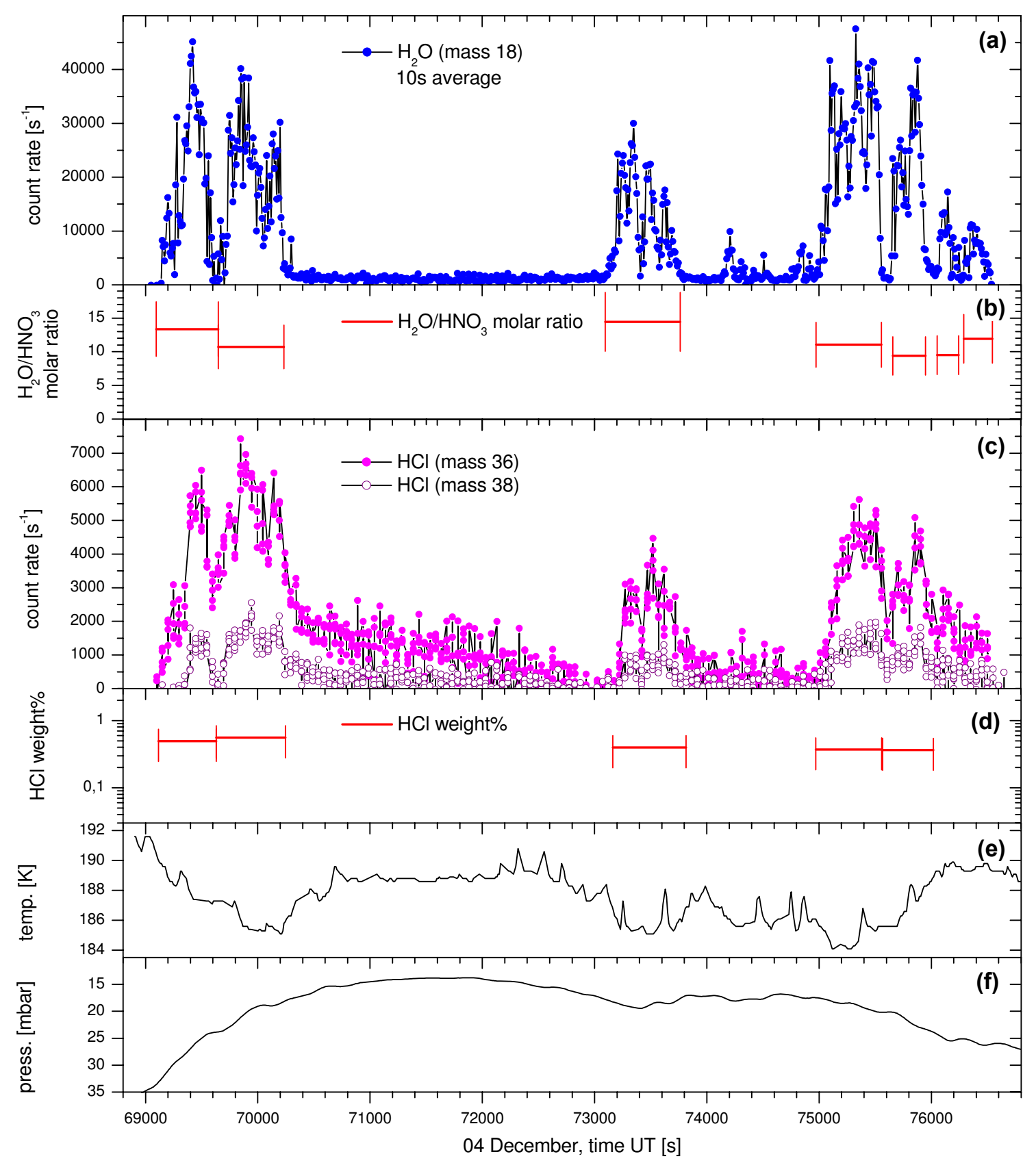

Fig. 2. (a) Water contained in $\mathrm{PSC}$ particles measured on mass $18\left(\mathrm{H}_{2} \mathrm{O}\right)$, averaged over $10 \mathrm{~s}$. (b) $\mathrm{H}_{2} \mathrm{O} / \mathrm{HNO}_{3}$ molar ratios derived from measurements. (c) $\mathrm{HCl}$ contained in liquid PSC particles measured on masses $36\left(\mathrm{H}^{35} \mathrm{Cl}\right)$ and $38\left(\mathrm{H}^{37} \mathrm{Cl}\right)$. (d) $\mathrm{HCl}$ weight\% derived from measurements. (e) Measured atmospheric temperature. (f) Measured atmospheric pressure.

where the particle beam is stopped. Over the whole altitude range large particles $>2.0 \mu \mathrm{m}$ existed, however, a broad middle layer from 500 to $580 \mathrm{~K}$ potential temperature was dominated by numerous liquid particles masking the embedded large particles. The low concentration of large solid particles above and below the middle layer was also evident by a high color index.

The main constituents of PSC particles are water and nitric acid measured with the ACMS on mass $18\left(\mathrm{H}_{2} \mathrm{O}^{+}\right)$and on mass $63\left(\mathrm{HNO}_{3}^{+}\right)$and $46\left(\mathrm{NO}_{2}^{+}\right)$. Of particular interest are the signals related to $\mathrm{HCl}$ (mass 36 and 38). When clouds were encountered, signals of those PSC particle related masses rose dramatically in the mass spectrometer. Figure 2 shows in panel (c) experimental evidence that indeed $\mathrm{HCl}$ contained in PSC particles was measured. Laboratory calibrations have shown that $\mathrm{HCl}$ undergoes little fractionation in the electron impact ion source and therefore masses 36 $\left(\mathrm{H}^{35} \mathrm{Cl}\right)$ and $38\left(\mathrm{H}^{37} \mathrm{Cl}\right)$ can be used to identify hydrochloric 
acid within the mass spectrum with the unique isotope ratio of 3.1. Because it is a trace gas, caution must be applied when the data gathered on those mass peaks are interpreted. ${ }^{36} \mathrm{Ar}$ and ${ }^{38} \mathrm{Ar}$ contributions, besides those from the instrument background, must be subtracted to derive a net $\mathrm{HCl}$ signal. From measurements of $\mathrm{N}_{2}$ and ${ }^{40} \mathrm{Ar}$, which are occasionally monitored, the potential abundance of the two lighter Ar isotopes can be estimated. In addition, their isotope ratio ${ }^{36} \mathrm{Ar}:{ }^{38} \mathrm{Ar}$ equals 5.5 , while the ratio for ${ }^{35} \mathrm{Cl}:{ }^{37} \mathrm{Cl}$ is 3.1. This ratio, as an exclusive indicator for $\mathrm{HCl}$, has been verified during laboratory calibrations of the mass spectrometer. The general background correction was obtained when the gondola traveled outside the clouds. The average $\mathrm{Cl}$ isotope ratio, although with considerable scatter, is $3.2 \pm 0.3$ and thus identifies the isotopes of $\mathrm{HCl}$. Both mass peaks are only present during those parts of the flight when the water signal increased during the encounter with stratospheric clouds (panel a).

Calibrations of the mass spectrometer before and - if possible - after the balloon flight are a critical component in the analysis of the data. As in past experiments the instrument was calibrated using a dynamic flow system (Kohlmann, 2000; Schreiner et al., 2002), which permits to admit well known amounts of gases that include $\mathrm{N}_{2}, \mathrm{Ar}, \mathrm{H}_{2} \mathrm{O}, \mathrm{HNO}_{3}$, and $\mathrm{HCl}$ to the mass spectrometer ion source. The configuration and the temperature of the evaporation sphere and attached mass spectrometer ion source were identical during calibration and flight. Since the payload was recovered in good condition the instrument was also re-calibrated for the same gases of interest. Fortunately, the sensitivity of the instrument was found to be nearly the same as before the flight. We have only indirect checks on the instrument performance during the flight when atmospheric gases serve as monitors for its stability. Overall, the performance of the mass spectrometer during the balloon flight reported in this paper appears to be stable with no changes in sensitivity detected. Therefore the average molar ratios $\mathrm{H}_{2} \mathrm{O} / \mathrm{HNO}_{3}$ and the abundance of $\mathrm{HCl}$ in liquid particles will be based on those calibrations. The ACMS was in all technical aspects identical to those instruments flown in previous flights. As mentioned above the cleanliness of the system was improved and the ionizing electron current increased for a higher ion beam intensity.

\section{Results}

The discussion of results will start with the appearance and molar ratios of STS particles followed by a description of $\mathrm{HCl}$ in liquid aerosols.

\subsection{STS particles and atmospheric temperatures}

On 4 December 2002 PSCs existed between 490 and $610 \mathrm{~K}$ potential temperature, approximately from 20 to $27 \mathrm{~km}$ al- titude. Closely correlated PSC particle properties were detected with the different instruments, as shown in Fig. 1. The cloud was dominated by a broad layer of mostly liquid particles ranging from 500 to $580 \mathrm{~K}$ potential temperature. These relatively small particles appear in high number concentrations with nearly all background aerosols activated. The ACMS responded with continuous high count rates of water and nitric acid signals. Further characteristics are a high backscatter ratio, a low color index, and low depolarization. Low concentrations of considerably larger, probably solid particles were present over the whole altitude range wherever $T<T_{\mathrm{NAT}}$ as can be seen from the optical particle counter measurements. This is also supported by the volume depolarization. Although the depolarization values are low, they are not as low as expected for a pure liquid cloud. Due to the reduced transmission efficiency of the aerodynamic lens for such large particles $(r>1.0 \mu \mathrm{m})$ only a few were measured with the ACMS. For a composition analysis, however, the counting statistic is too low. They did not cause any interference with the detection of liquid particles since the partial pressures inside the evaporation sphere are always low and very similar to the pressures during calibrations.

In the backscatter data these low concentrations of solid particles are masked by the high number density of liquid particles. They can only be identified at the top and the bottom of the liquid layer by low backscatter, but higher color index and depolarization, when the temperatures become too high for the existence of liquid particles. This gives rise to a "sandwich" structure, which has been previously observed by LIDAR measurements (Shibata et al., 1997; Stein et al., 1999; Biele et al., 2001). Here it seems clear that this structure is simply determined by the growth of STS as the temperature decreases in the middle of the cloud, rather than some features related to the development of the solid-phase particles.

One parameter of special interest in PSC research is the molar ratio of $\mathrm{H}_{2} \mathrm{O} / \mathrm{HNO}_{3}$ of aerosol particles. The calibrations before and after the flight are intended to derive those ratios with a high accuracy. $\mathrm{HNO}_{3}$ interacts, unfortunately, with the walls of the evaporation sphere and probably less with the ion source. During calibrations sufficient time is available to achieve equilibrium between adsorption and desortption processes. After a cloud encounter, however, a slowly decreasing signal of $\mathrm{HNO}_{3}$ is observed while the water signal drops rapidly. We selected in our analysis of mixing ratios specific time intervals by means of the high water signals and added the part of nitric acid which is trailing that interval to the signal observed within. Thus, only average values are determined. During those periods altitude and temperature may change and because of the high sensitivity of dissolved $\mathrm{HNO}_{3}$ in liquid particles to temperature, the uncertainty in mixing ratios is high and will make a straightforward comparison with models difficult. When average molar ratios for various cloud encounters are compared with model predictions (Carslaw et al., 1995) observed 


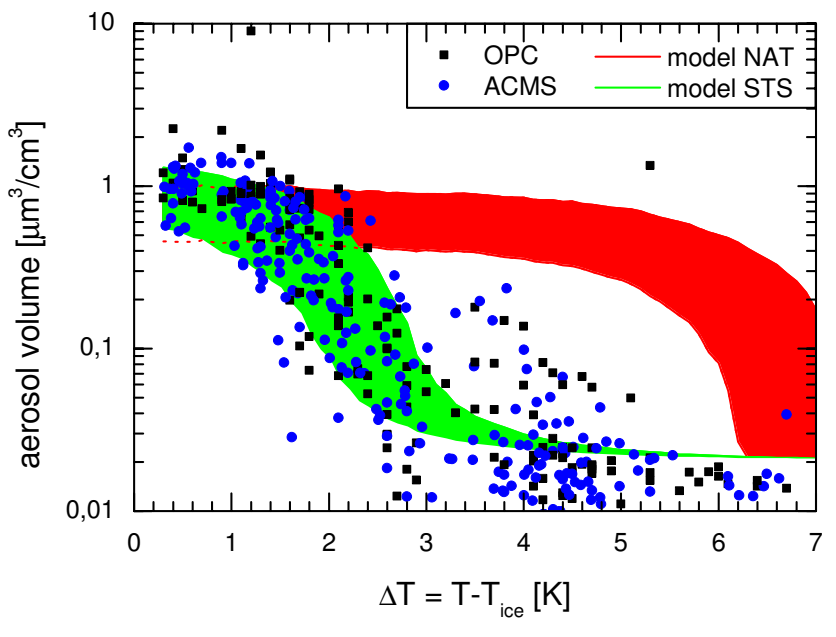

Fig. 3. Aerosol volume measured by the optical particle counters and derived from the aerosol composition mass spectrometer as a function of temperature difference $T-T_{\text {ice }}$. Measurements are compared with aerosol volumes for STS and NAT predicted by model calculations, using Carslaw et al. (1995). The measured water vapor mixing ratio was used, the sulfuric acid mixing ratio was derived form the background sulfate aerosol measurement, and a range of 5 to $11 \mathrm{ppbv}$ gas phase $\mathrm{HNO}_{3}$ was assumed.

values are higher. Because of the limitations discussed above which also include the uncertainty in the ambient $\mathrm{HNO}_{3}$ gas phase mixing ratio (assumed to be $11 \mathrm{ppbv}$ ), a more detailed comparison is not possible. In Fig. 2, panel (b) average ratios for a number cloud passages are shown.

Both ACMS and OPC data allow to derive the total aerosol volume. Panel (e) in Fig. 1 shows the measured aerosol volume for the first ascent. For the ACMS the fast and accurate water signal, the laboratory calibrations, and the measured molar ratios were used to asses the aerosol volume. Based on laboratory calibrations small corrections for the transmission efficiency of the lens of about $5 \%$ were applied. The aerosol volumes based on measurements of the two instruments agree very well. For comparison predictions for STS particles from the model by Carslaw et al. (1995) are shown assuming 11 ppbv gas phase $\mathrm{HNO}_{3}$ and using the measured water mixing ratio (ranging from 5 to 6 ppmv) and the sulfuric acid mixing ratio derived form the background sulfate aerosol measurement ( 0.08 to $0.18 \mathrm{ppbv}$, altitude dependent). Gas phase $\mathrm{HNO}_{3}$ was not monitored on the gondola. Measurements of the MIPAS-B instrument that was flown two days later reveal $\mathrm{HNO}_{3}$ values of $10 \mathrm{ppbv}$ in areas with temperatures above $T_{\mathrm{STS}}$, but between $5-10 \mathrm{ppbv}$ due to the uptake in the STS particles. The high atmospheric mixing ratio is consistent with the early period of PSC observations prior to any denitrification.

Figure 3 shows the change in aerosol volume for the transit from inside the layer with liquid particles to outside at the top of the cloud around $590 \mathrm{~K}$ potential temperature as a function of temperature difference $\Delta T=T-T_{\text {ice }}$. This demon- strates, how the existence of STS particles is driven by ambient temperature. As soon as temperature drops below a certain threshold the sulfate background aerosols begin to swell due the uptake of water and nitric acid and become STS droplets. If they have enough time they reach equilibrium, which here seems to be the case. It should be noted, however, that the observations do not strictly follow the temporal evolution of the growth or evaporation of the droplets, but show the transition from warmer air masses to a layer with lower temperature where STS can exist. Figure 3 also compares the measurements with model predictions of the total aerosol volume for STS and NAT particles for a range of 5 to $11 \mathrm{ppbv} \mathrm{HNO}_{3}$ calculated from the model by Carslaw et al. (1995) where equilibrium conditions are assumed. The uncertainty in the $\mathrm{HNO}_{3}$ measurements has little influence on the calculation of the aerosol volumes.

There are also data that do not fit the STS nor NAT equilibrium model predictions. At the bottom and top of the PSC (500 and $610 \mathrm{~K}$ potential temperature) the aerosol volumes lie above the theoretical calculations for STS, but below NAT. These data points result from larger particles, that are present over the whole altitude range of the PSC as can be seen clearly in the size distribution measured by the OPC, Fig. 1, panel (c). The depolarization measurements let us conclude that these particles are solid. They are masked in the ACMS measurements and the backscattersonde data because of the large volume and surface area, respectively, of small liquid droplets that appear when temperature is below the STS threshold. The large solid particles could be of NAT composition, but their volume did not reach equilibrium expected for NAT, while, as shown above, the volume calculations suggest that the measured STS droplets are in equilibrium with their environment. The deviation of the large solid particles from NAT equilibrium are also reproduced by model calculations presented in the accompanying publication by Larsen et al. (2004).

\subsection{First measurements of $\mathrm{HCl}$ in STS particles}

The dissolved $\mathrm{HCl}$ in particles is highly sensitive to atmospheric temperature and pressure. Over a small temperature range the $\mathrm{HCl}$ solubility will increase dramatically: Between 195 and $187 \mathrm{~K}$, according to the model by Carslaw et al. (1995), the $\mathrm{HCl}$ content will change by at least a factor of 100. Similarly, substantial changes result from changes in altitude, all related in the end to the change in $\mathrm{H}_{2} \mathrm{SO}_{4}$ and the water activity of the aerosol. $\mathrm{HCl}$ has a similar problem as $\mathrm{HNO}_{3}$ when particles evaporate inside the small sphere. After a cloud passage the signals on mass 36 and 38 slowly decrease while water drops fast (Fig. 2, panels (a) and (c), time interval 70 300-72 500). Our analysis of $\mathrm{HCl}$ was very similar to the analysis of $\mathrm{HNO}_{3}$. The decreasing signals were added to the amount measured when within a cloud and thus average values (in weight $\%$ ) are derived. They are shown in Fig. 2d. It is clear that the change in atmospheric 
temperatures within a time frame will strongly influence the dissolved $\mathrm{HCl}$ and again caution must be applied when comparisons with models are made. The average amounts present fall within 1 and 0.1 weight $\%$.

\section{Conclusions}

Synoptic scale polar stratospheric clouds that formed without the influence of mountain lee waves were observed in early winter 2002/2003. Measurements described here as well as observations from previous campaigns (Deshler et al., 2003b) show clearly that over wide areas solid and liquid particles coexist in the Arctic stratosphere. Relatively large solid aerosol particles with low number density, most likely composed of NAT, existed over a broad altitude range when $T<T_{\text {NAT }}$. When temperatures fell below $T_{\mathrm{STS}}$ liquid STS particles immediately appeared. The high number density and volume, respectively, of the small droplets masked the solid particles for identification with backscattersondes, creating the appearance of a sandwich structure of the PSC with a broad layer of liquid droplets surrounded by solid particles at the bottom and on top. The observations here and in December 2002 suggest that the presence of solid particles is almost independent of the temperature at the time of the observation as long as $T<T_{\mathrm{NAT}}$, but it may strongly depend on the temperature history of the air parcels. In contrast, the measurements show a close correlation of the appearance of liquid STS droplets with local ambient temperature. We support, particularly because of the accurate temperature measurements, that the predictions made by current STS models (Carslaw et al., 1995; Tabazadeh et al., 1994) are accurate in describing the growth of liquid STS particles as a function of temperature in the polar stratosphere.

$\mathrm{HCl}$ in liquid particles was measured for the first time. The unique isotope ratio of chlorine permits a clear identification of $\mathrm{HCl}$ dissolved in condensed phase material. The adsorption/desorption processes within the instrument and the unknown gas phase mixing ratio (assumed to be $1 \mathrm{ppbv}$ ) make a precise comparison with model predictions difficult. With the assumptions stated above the average amount of $\mathrm{HCl}$ in liquid particles is below 1 weight $\%$ within a temperature range of 3 degrees above $T_{\text {ice }}$.

Acknowledgements. We like to thank the French balloon team from the the Centre National d'Etudes Spatiales, especially the late P. Faucon, for their excellent work to guide our payload through PSCs, supported by the Swedish Space Corporation. We are in debt to our machine and electronic shop personnel for their skillful work and last not least to B. Jacob, V. Haury, and O. Indris for their support in composing this paper. This research was supported by the Commission of the European Union through the Environmental and Climate Program, the German Bundesministerum für Bildung und Forschung (BMBF, AFO2000), and the US National Science Foundation (OPP-0095158).

Edited by: U. Pöschl

\section{References}

Adriani, A., Cairo, F., Viterbini, M., Mandolini, S., Pulvirenti, L., and Di Donfrancesco, G.: Multiwavelength aerosol scatterometer for airborne experiments to study the optical properties of stratospheric aerosol, J. Atmos. and Oceanic Tech., 16, 1329, 1999.

Biele, J., Tsias, A., Luo, B. P., Carslaw, K. S., Neuber, R., Beyerle, G., and Peter, T.: Non-equilibrium coexistence of solid and liquid particles in Arctic stratosperic clouds, J. Geophys. Res., 106, 22 991-23 007, 2001.

Carslaw, K. S., Luo, B. P., Clegg, S. L., Peter, T., Brimblecombe, P., and Crutzen, P. J.: Stratospheric aerosol growth and $\mathrm{HNO}_{3}$ gas phase depletion from coupled $\mathrm{HNO}_{3}$ and water uptake by liquid particles, Geophys. Res. Lett., 21, 2479-2482, 1994.

Carslaw, K. S., Luo, B. P., and Peter, T.: An analytic expression for the composition of aqueous $\mathrm{HNO}_{3}-\mathrm{H}_{2} \mathrm{SO}_{4}$ stratospheric aerosols including gas phase removal of $\mathrm{HNO}_{3}$, Geophys. Res. Lett., 22, 1877-1880, 1995.

Carslaw, K. S., Peter, T., and Clegg, S. L.: Modeling the composition of liquid stratospheric aerosols, Rev. Geophys., 35, 125-154, 1997.

Deshler, T. and Oltmans, S. J.: Vertical profiles of volcanic aerosol and polar stratospheric clouds above Kiruna, Sweden: Winters 1993 and 1995, J. Atmos. Chem., 30, 11-23, 1998.

Deshler, T., Hervig, M. E., Hofmann, D. J., Rosen, J. M., and Liley, J. B.: Thirty years of in situ stratospheric aerosol size distribution measurements from Laramie, Wyoming $\left(41^{\circ} \mathrm{N}\right)$, using balloonborne instruments, J. Geophys. Res., 108, 4167, 2003 a.

Deshler, T., Larsen, N., Weisser, C., Schreiner, J., Mauersberger, K., Cairo, F., Adriani, A., Di Donfrancesco, G., Ovarlez, J., Ovarlez, H., Blum, U., Fricke, K. H., and Dörnbrack, A.: Large nitric acid particles at the top of an Arctic stratospheric cloud, J. Geophys. Res., 108, 4517, 2003 b.

Drdla, K., Schoeberl, M. R., and Browell, E. V.: Microphysical modelling of the 1999-2000 Arctic winter: 1. Polar stratospheric clouds, denitrification, and dehydration, J. Geophys. Res., 107, 8312, doi:10.1029/2001JD000782, 2003.

Eidhammer, T. and Deshler, T.: Technical Note: Evaporation of polar stratospheric cloud particles, in situ, in a heated inlet, Atmos. Chem. Phys., 5, 97-106, 2005.

Fahey, D. W., Gao, R. S., Carslaw, K. S., Kettleborough, J., Popp, P. J., Northway, M. J., Holecek, J. C., Ciciora, S. C., McLaughlin, R. J., Thompson, T. L., Winkler, R. H., Baumgardner, D. G., Gandrud, B., Wennberg, P. O., Dhaniyala, S., McKinney, K., Peter, T., Salawitch, R. J., Bui, T. P., Elkins, J. W., Webster, C. R., Atlas, E. L., Jost, H., Wilson, J. C., Herman, R. L., Kleinböhl, A., and von König, M.: The detection of large $\mathrm{HNO}_{3}$-containing particles in the winter Arctic stratosphere, Science, 291, 10261031, 2001.

Gandrud, B. W., Sperry, P. D., Sanford, L., Kelly, K. K., Ferry, G. V., and Chan, K. R.: Filter measurement results from the Airborne Antarctic Ozone Experiment, J. Geophys. Res., 94, 11 285-11 297, 1989.

Hanson, D. and Mauersberger, K.: Laboratory studies of the nitric acid trihydrate: Implications for the south polar stratosphere, Geophys. Res. Lett., 15, 855-858, 1988. 
Hanson, D. R. and Ravishankara, A. R.: Uptake of $\mathrm{HCl}$ and $\mathrm{HOCl}$ onto sulfuric acid: Solubilities, diffusivities, and reaction, J. Phys. Chem., 97, 12 309-12 319, 1993.

Hanson, D. R. and Ravishankara, A. R.: Reactive uptake of $\mathrm{ClONO}_{2}$ onto sulfuric acid due to reaction with $\mathrm{HCl}$ and $\mathrm{H}_{2} \mathrm{O}$, J. Phys. Chem, 98, 5728-5735, 1994.

Kohlmann, A.: Kalibration von Massenspektrometern zur AerosolAnalyse durch dynamische Expansion von Wasserdampf, $\mathrm{HNO}_{3}$ und $\mathrm{HCl}$, Dissertation, Ruprecht-Karls-Universität Heidelberg, 2000.

Koop, T., Luo, B. P., Biermann, U. M., Crutzen, P. J., and Peter, T.: Freezing of $\mathrm{HNO}_{3} / \mathrm{H}_{2} \mathrm{SO}_{4} / \mathrm{H}_{2} \mathrm{O}$ solutions at stratospheric temperatures: Nucleation statistics and experiments, J. Phys. Chem. A, 101, 1117-1133, 1997.

Koop, T., Luo, B. P., Tsias, A., and Peter, T.: Water activity as the determinant for homogeneous ice nucleation in aqueous solutions, Nature, 406, 611-614, 2000.

Larsen, N., Høyer Svendsen, S., Knudsen, B. M., Voigt, C., Weisser, C., Kohlmann, A., Schreiner, J., Mauersberger, K., Deshler, T., Kröger, C., Rosen, J. M., Kjome, N. T., Adriani, A., Cairo, F., Di Donfrancesco, G., Ovarlez, J., Ovarlez, H., Dörnbrack, A., and Birner, T.: Microphysical mesoscale simulations of polar stratospheric cloud formation constrained by in-situ measurements of chemical and optical cloud properties, J. Geophys. Res., 107, 8301, 2002.

Larsen, N., Knudsen, B. M., Høyer Svendsen, S., Deshler, T., Rosen, J. M., Kivi, R., Weisser, C., Schreiner, J., Mauersberger, K., Cairo, F., Ovarlez, J., Oelhaf, H., and Spang, R.: Formation of solid particles in synoptic-scale Arctic PSCs in early Winter 2002/2003, Atmos. Chem. Phys., 4, 2001-2013, 2004.

Luo, B. P., Clegg, S. L., Peter, T., Müller, R., and Crutzen P. J.: $\mathrm{HCl}$ solubility an liquid diffusion in aqueous sulfuric acid under stratospheric conditions, Geophys. Res. Lett., 21, 49-52, 1994.

Newman, P. A., Harris, N. R. P., Adriani, A., Amanatidis, G. T., Anderson, J. G., Braathen, G. O., Brune, W. H., Carslaw, K. S., Craig, M. S., DeCola, P. L., Guirlet, M., Hipskind, R. S., Kurylo, M. J., Küllmann, H., Larsen, N., Mégie, G. J., Pommereau, J.-P., Poole, L. R., Schoeberl, M. R., Stroh, F., Toon, O. B., Trepte, C. R., and van Roozendael, M.: An overview of the SOLVE/THESEO 2000 campaign, J. Geophys. Res., 107, 8259, 2002.

Ovarlez, J. and Ovarlez, H.: Stratospheric water vapor content evolution during EASOE, Geophys. Res. Lett., 21, 1235-1238, 1994.

Pueschel, R. F., Snetsinger, K. G., Goodman, J. K., Toon, O. B., Ferry, G. V., Oberbeck, V. R., Livingston, J. M., Verma, S., Fong, W., Starr, W. L., and Chan, K. R.: Condensed nitrate, sulfate, and chloride in Antarctic stratospheric clouds, J. Geophys. Res., 94, $11271-11284,1989$.
Rosen, J. M. and Kjome, N. T.: Backscattersonde: a new instrument for atmospheric aerosol research, Appl. Optics, 30, 1552-1561, 1991.

Schreiner, J., Schild, U., Voigt, C., and Mauersberger, K.: Focusing of Aerosols into a Particle Beam at Pressures from 10 to 150 Torr, Aerosol Sci. Technol., 31, 373-382, 1999a.

Schreiner, J., Voigt, C., Kohlmann, A., Arnold, F., Mauersberger, K., and Larsen, N.: Chemical analysis of polar stratospheric cloud particles, Science, 283, 968-970, 1999b.

Schreiner, J., Voigt, C., Zink, P., Kohlmann, A., Knopf, D., Weisser, C., Budz, P., and Mauersberger, K.: A mass spectrometer system for analysis of polar stratospheric aerosols, Rev. Sci. Instrum., 73, 446-452, 2002.

Schreiner, J., Voigt, C., Weisser, C., Kohlman, A., Mauersberger, K., Deshler, T., Kröger, C., Rosen, J., Kjome, N., Larsen, N., Adriani, A., Cairo, F., Di Donfrancesco, G., Ovarlez, J., Ovarlez, H., and Dörnbrack, A.: Chemical, microphysical, and optical properties of polar stratospheric clouds, J. Geophys. Res., 108 8313, doi:10.1029/2001JD000825, 2003.

Shibata, T., Iwasaka, Y., Fujiwara, M., Hayashi, M., Nagatani, M., Shiraishi, K., Adachi, H., Sakai, T., Susumu, K., and Nakura, N.: Polar stratospheric clouds observed by lidar over Spitsbergen in the winter 1994/1995: Liquid particles and vertical "sandwich" structure, J. Geophys. Res., 102, 10 829-10 840, 1997.

Stein, B., Wedekind, C., Wille, H., Immler, F., Müller, H., Wöste, L., del Guasta, M., Morandi, M., Stefanutti, L., Antonelli, A., Agostini, P., Rizi, V., Readelli, G., Mitev, V., Matthey, R., Kivi, R., and Kyrö, E.: Optical classification, existence temperatures, and coexistence of different polar stratospheric cloud types, J. Geophys. Res., 104, 23 983-23 993, 1999.

Tabazadeh, A., Turco, R. P., and Jacobson, M. Z.: A model for studying the composition and chemical effects of stratospheric aerosols, J. Geophys. Res., 99, 12 897-12 914, 1994.

Voigt, C., Schreiner, J., Kohlmann, A., Zink, P., Mauersberger, K., Larsen, N., Deshler, T., Kröger, C., Rosen, J., Adriani, A., Cairo, F., Di Donfrancesco, G., Viterbini, M., Ovarlez, J., Ovarlez, H., David, C., and Dörnbrack, A.: Nitric acid trihydate (NAT) in polar stratospheric clouds, Science, 290, 1756-1758, 2000.

Zhang, R., Wooldridge, P. J., and Molina, M. J.: Vapor pressure measurements for the $\mathrm{H}_{2} \mathrm{SO} 4 / \mathrm{HNO}_{3} / \mathrm{H}_{2} \mathrm{O}$ and $\mathrm{H}_{2} \mathrm{SO}_{4} / \mathrm{HCl} / \mathrm{H}_{2} \mathrm{O}$ systems: Incorporation of stratospheric acids into background sulfate aerosols, J. Phys. Chem., 97, 8541-8548, 1993. 